\title{
TU/e EmonOWEN

\section{Modified methods for off- and on-line determination of electroosmosis in capillary electrophoretic separations}

\section{Citation for published version (APA):}

van de Goor, A. A. A. M., Wanders, B. J., \& Everaerts, F. M. (1989). Modified methods for off- and on-line determination of electroosmosis in capillary electrophoretic separations. Journal of Chromatography, 470(1), 95104. https://doi.org/10.1016/S0021-9673(00)94203-1

DOI:

10.1016/S0021-9673(00)94203-1

Document status and date:

Published: 01/01/1989

\section{Document Version:}

Publisher's PDF, also known as Version of Record (includes final page, issue and volume numbers)

\section{Please check the document version of this publication:}

- A submitted manuscript is the version of the article upon submission and before peer-review. There can be important differences between the submitted version and the official published version of record. People interested in the research are advised to contact the author for the final version of the publication, or visit the $\mathrm{DOI}$ to the publisher's website.

- The final author version and the galley proof are versions of the publication after peer review.

- The final published version features the final layout of the paper including the volume, issue and page numbers.

Link to publication

\section{General rights}

Copyright and moral rights for the publications made accessible in the public portal are retained by the authors and/or other copyright owners and it is a condition of accessing publications that users recognise and abide by the legal requirements associated with these rights.

- Users may download and print one copy of any publication from the public portal for the purpose of private study or research.

- You may not further distribute the material or use it for any profit-making activity or commercial gain

- You may freely distribute the URL identifying the publication in the public portal.

If the publication is distributed under the terms of Article 25fa of the Dutch Copyright Act, indicated by the "Taverne" license above, please follow below link for the End User Agreement:

www.tue.nl/taverne

Take down policy

If you believe that this document breaches copyright please contact us at:

openaccess@tue.nl

providing details and we will investigate your claim. 

ELECTROOSMOSIS IN CAPILLARY ELECTROPHORETIC SEPARATIONS

\author{
A. A. A. M. VAN DE GOOR*, B. J. WANDERS and F. M. EVERAERTS
}

Laboratory of Instrumental Analysis, Eindhoven University of Technology, P.O. Box 513,5600 MB Eindhoven (The Netherlands)

\title{
SUMMARY
}

Two modified methods for measuring the $\zeta$-potential and electroosmotic flow in capillaries for electrophoretic or electrochromatographic separations are discussed. Streaming potential measurements with computer control and data acquisition can be used off-line for rapid screening of the behaviour of capillaries. To test the equipment, the variation of the $\zeta$-potential with $\mathrm{pH}$ was performed and the characteristics of the system are discussed. Weighing measurements were performed on-line. The variation of the measurements with increased electric field strength are shown. For both methods the reproducibility and the accuracy are discussed.

\section{INTRODUCTION}

In the last 15 years electroosmosis has been introduced as a way of transporting the mobile phase in capillary chromatography ${ }^{1}$ and the electrolyte solution in capillary electrophoresis ${ }^{2}$. The benefit for chromatography is the flat velocity profile of electroosmotic flow (EOF) compared with the parabolic flow profile arising from mechanical pumping. This often leads to a decrease in band broadening and, therefore, to higher plate numbers ${ }^{3,4}$. The advantage for electrophoresis is the streaming electrolyte, which can be used to sweep all ions towards the detector irrespective of the sign of their charge. In this instance the absolute value of the electroosmotic velocity must be higher than the absolute value of the electrophoretic velocities of each of the sample components. If the electroosmosis is oriented opposite to the electrophoretic direction of the ion and has a lower absolute value, then a counter flow of electrolyte occurs $^{5,6}$. This always leads to an increase in separation time to obtain full resolution.

EOF in capillaries originates from an electric double layer between the capillary wall and the liquid present in the capillary. If an electric field is applied over the length of the capillary, the liquid starts to flow. However, other electrokinetic phenomena, such as electrophoresis and surface conductance, appear simultaneously. These phenomena influence the electroosmosis. Therefore, many parameters characterize the separation. Understanding, predicting and controlling the EOF, therefore, demands a measuring technique that resembles closely the experimental separation conditions. 
Several methods have already been applied. A neutral marker molecule can be used to estimate the $\mathrm{EOF}^{7-9}$. This molecule is transported by the liquid flow and should not be influenced by the electric field gradient or any adsorption effect. This method, however, meets the same problems as finding a good zero retention time $\left(t_{\mathbf{R} 0}\right)$ marker, in liquid chromatography.

Colloidal particles, of the same material as the capillary, can be used ${ }^{10}$. Their electrophoretic migration gives information about the electrokinetic behaviour of the material, although a large difference exists between this method and the separation conditions.

Streaming potentials can be used to characterize the EOF ${ }^{1-14}$. Reijenga et al. ${ }^{15}$ applied this method to predict the effect of the EOF on the boundary conditions in isotachophoresis.

Altria and Simpson ${ }^{16,17}$ introduced the idea of weighing the electrolyte which leaves the capillary, giving direct information about the EOF. This technique, however, gives only time-averaged results. On the other hand, no additives are needed to determine the flow. Therefore, it resembles most closely the experimental conditions.

We have adapted the method of Reijenga et al. ${ }^{15}$ and modified it to a computer-controlled measuring system, which allows the changes in the capillary with time to be monitored. We also modified the technique of Altria and Simpson ${ }^{16,17}$ to an on-line measuring system. Both techniques are discussed after a brief theoretical explanation.

\section{THEORY}

The theory of electrokinetic phenomena such as electroosmosis, electrophoresis, surface conductance and streaming potential has been discussed extensively elsewhere ${ }^{11,12,18,19}$. Some necessary aspects will be pointed out in order to understand the techniques described. When an insulator is immersed in a liquid, an electric double layer results at the interface. This is caused by the charged surface arising from ionic substances, which can be adsorbed, or from charged groups that are introduced by dehydration. Because of this charged surface, ionic species with similar charge sign

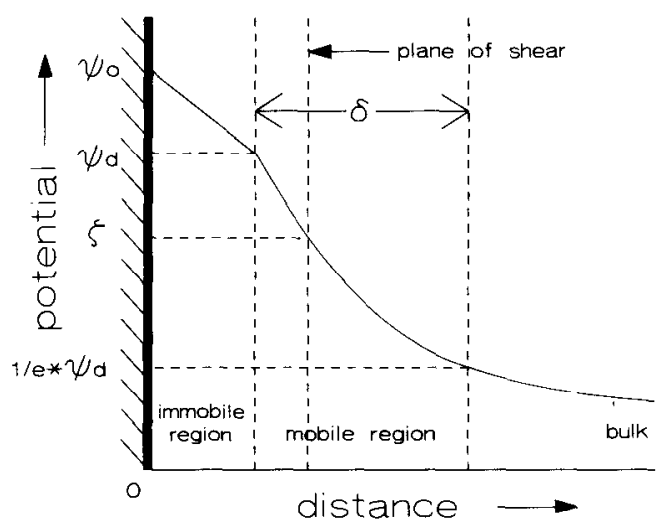

Fig. I. Representation of the double layer. 
(co-ions) are repelled from the surface while species with opposite charge sign (counter ions) are attracted. This results in the so-called electric double layer. Part of these counter ions are immobilized by a strong interaction with the surface. Others, which reach further into the liquid, form the mobile, diffuse part. Because no electroneutrality exists within the electric double layer, a potential gradient arises as described in the Gouy-Chapman theory.

Fig. 1 shows schematically the potential gradient at the solid-liquid interface. $\psi_{0}$ is the electric potential at the surface. From this surface the potential decreases, while entering the liquid, because the space charge diminishes. The potentials at certain planes are defined to characterize the double layer. $\psi_{\mathrm{d}}$ is the potential at the interface between the immobile and mobile parts of the double layer. The thickness of the double layer, $\delta$, is defined as the length between the two planes where the potential is $(1 / \mathrm{e}) \psi_{\mathrm{d}}$ and $\psi_{\mathrm{d}}$, respectively ${ }^{11}$. A third characteristic potential is the $\zeta$-potential, which is the potential at the plane of shear, occurring when the liquid is forced to move.

The described interface is found in capillary electrochromatography and capillary electrophoresis between the capillary wall and the liquid present in the capillary. When an external electric field is applied tangentially to the surface, several electrokinetic phenomena arise. Bulk electrolyte conductance and surface conductance are a direct consequence of the electric field. Under operational conditions the surface conductance can usually be ignored. Electroosmosis arises from the movement of the ions in the diffuse part of the double layer. The electrolyte is dragged along by these ions, which causes a liquid flow in the direction of the counter ions.

The Smoluchowski equation (eqn. 1) can be used to describe the velocity of the liquid flow. It should be stated that this equation is valid only for capillary systems in which the diameter is considerably larger than the double layer thickness. Also, a uniform electrolyte in the system and a constant $\zeta$-potential over the whole capillary surface is expected ${ }^{20}$.

$$
v_{\mathrm{eo}}=\frac{\varepsilon \zeta E}{\eta}
$$

where $v_{\text {eo }}$ is the electroosmotic velocity $(\mathrm{m} / \mathrm{s}), \varepsilon$ the dielectric constant $(\mathrm{F} / \mathrm{m}), \eta$ the viscosity of the electrolyte $(\mathrm{kg} / \mathrm{m} \cdot \mathrm{s}), \zeta$ represents the $\zeta$-potential (V) of the capillary wall and $E$ is the electric field strength $(\mathrm{V} / \mathrm{m})$ over the capillary. When, instead of an electric field, a pressure gradient is applied tangential to the solid-liquid interface, a potential difference, the streaming potential, is the result. The streaming potential, $E_{\text {st }}$, can also be correlated with the $\zeta$-potential of the surface and thus to the EOF by the equation

$$
E_{\mathrm{st}}=\frac{\Delta P \varepsilon \zeta}{\eta \kappa}
$$

were $\Delta P$ is the pressure drop $\left(\mathrm{N} / \mathrm{m}^{2}\right)$ over the system and $\kappa$ is the specific conductance $(1 / \Omega \mathrm{m})$ of the electrolyte. Eqn. 2 can only be used when surface conductance can be neglected with respect to the specific conductance of the electrolyte. A laminar flow within the capillary is also required. 


\section{EXPERIMENTAL}

\section{Streaming potentials}

The experimental setup used was similar to that in the method of Reijenga et al. ${ }^{15}$. The situation is depicted in Fig. 2.

A capillary was fitted between two electrolyte vessels through plastic plugs. $\mathrm{Ag} / \mathrm{AgCl}$ electrodes $(40 \times 1 \mathrm{~mm})$, made according to the method of Thomson ${ }^{21}$, were placed in the vessels. The vessels contained connections allowing nitrogen to enter for pumping the electrolyte.

From eqn. 2, it is clear that high streaming potentials and, therefore, high resolution can be obtained by using high pressure drops. Therefore, care should be taken with chosing proper capillary dimensions. Using PTFE capillaries the pressure applied is limited to $1 \mathrm{~atm}$ because of the porosity of the capillary wall. This pressure drop, on the other hand, limits the maximum length of the capillary because of the minimum liquid flow required. However, to obtain a laminar flow during at least $90 \%$ of the capillary, a minimum length of $20 \mathrm{~cm}$ (I.D. $300 \mu \mathrm{m}$ ) was necessary ${ }^{13}$. The nitrogen pressure was switched using two magnetic valves, controlled by a computer, through an analytical interface (Perkin-Elmer, Norwalk, CT, U.S.A.).

Streaming potentials were measured by connecting the electrodes directly to a high-input impedance $\left(10^{12} \Omega\right) \mathrm{mV}$ meter (PW9414; Philips, Eindhoven, The Netherlands). The signal was then both recorded on a BD4l strip-chart recorder (Kipp \& Zonen, Delft, The Netherlands) and sent to an Apple IIe computer (Apple Computer, Cupertino, CA, U.S.A.) through the same interface.

The following cycles were performed. First, pressure was applied to one of the vessels during a period of $20 \mathrm{~s}$. In this time interval the potential difference across the capillary had time to stabilize and the streaming potential was read and stored. In the following $20 \mathrm{~s}$ the flow was forced in the opposite direction by applying the pressure to

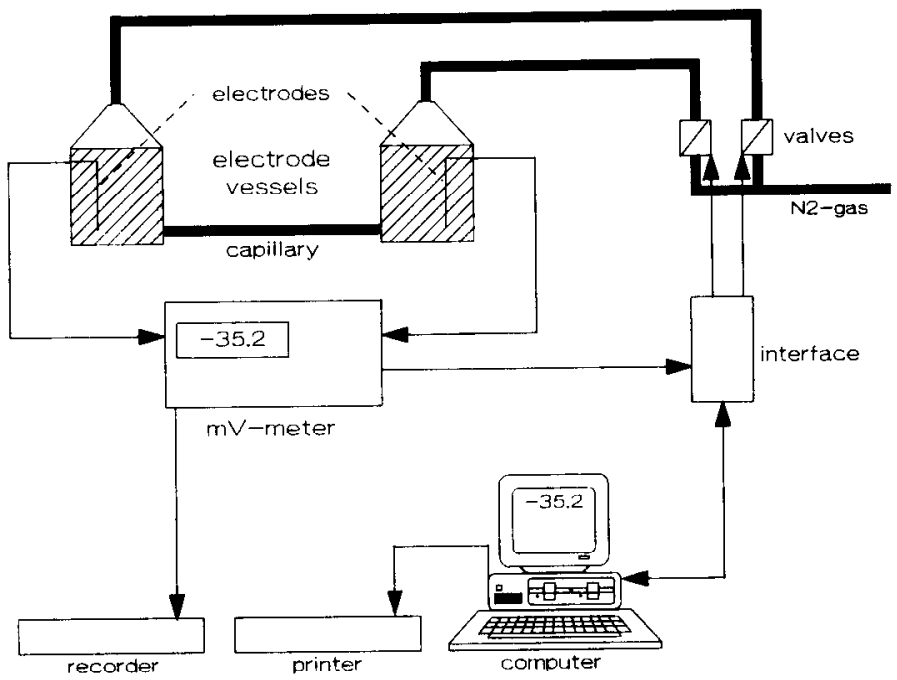

Fig. 2. Experimental setup used for streaming potential measurements. 


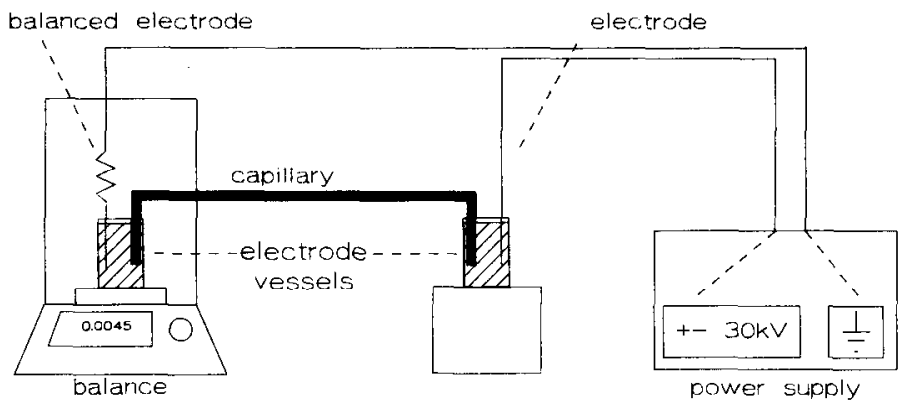

Fig. 3. Experimental setup used for weighing measurements of electroosmotic flow.

the other vessel. Again the streaming potential was measured. Finally, no pressure was applied for another $20 \mathrm{~s}$. The potential difference between the electrodes was measured and used as a reference. By this procedure an acceptable constant liquid level in the vessels and, therefore, a constant liquid-electrode contact surface area was obtained. This procedure also minimizes disturbances by gravity flow and corrects for asymmetry between the electrolyte vessels. The streaming potential was calculated by averaging the absolute value of both potential differences, corrected for the reference value.

$\zeta$-Potentials were calculated (eqn. 2) using the specific conductivity of the solution, measured off-line with a digital conductivity meter (CDM83; Radiometer, Copenhagen, Denmark).

\section{Weighing}

The weighing setup is shown schematically in Fig 3. Again the capillary was fitted in a similar way between the electrode vessels. The electrodes in those measurements were made of platinum wire $(0.2 \mathrm{~mm}$ diameter $)$. The grounded electrolyte vessel was placed directly on a Model MP8-1 microbalance (Sartorius, Göttingen, F.R.G.). A high voltage was applied over the capillary using a Model HN 30000-1 high-voltage power supply (Heinzinger, Rosenheim, F.R.G.) in the constant-voltage mode.

The electrodes had no contact with the vessel and even a spring was used to avoid any disturbances, e.g., contraction of the capillary when an electric field is applied. Also, the capillary was isolated from the balance to prevent current leakage. The change in weight could be read directly from a display, from which the EOF could be calculated.

First, the levels of the electrolyte in both vessels were brought to the same height using gravity flow. This position was used as the starting position for all experiments. Next, voltage was applied to the system, causing an EOF. The change in weight in the vessel on the balance was registered every $5 \mathrm{~min}$. This was sufficient to suppress errors occurring from instability in the read-out. Next the flow was forced in the opposite direction until the starting point was reached again. The same procedure was repeated but, to compensate for any asymmetry in the system, the polarity was changed. Finally, a run was performed without applying any voltage to correct for the gravity 
TABLE I

$0.01 M$ HYDROCHLORIC ACID ELECTROLYTE SOLUTIONS USED

\begin{tabular}{lll}
\hline$p H$ & Buffer ion & $\kappa(1 / \Omega m)$ \\
\hline 3.0 & B-Alanine & 0.1219 \\
3.5 & $\beta$-Alanine & 0.1000 \\
4.8 & Creatine & 0.0908 \\
6.0 & Histidine & 0.0893 \\
8.2 & Tris & 0.0853 \\
9.0 & Ammediol & 0.0863 \\
\hline
\end{tabular}

flow. The EOF was calculated by averaging the values of the two flows obtained, corrected for gravity flow, using the equation

$$
v_{\mathrm{eo}}=\frac{\Delta W}{\Delta t \rho A}
$$

where $\Delta W / \Delta t$ is the weight difference measured in a given time interval, $\rho$ the density of the electrolyte used and $A$ the cross-sectional area of the capillary.

Water used for preparing electrolytes was taken from a Milli-Q purification system (Millipore, Bedford, MA, U.S.A.). All reagents were of analytical-reagent grade and purchased from Merck (Darmstadt, F.R.G.). PTFE capillaries were purchased from HABIA (Breda, The Netherlands) (I.D. $300 \mu \mathrm{m}$ ). The lengths of the capillaries were 15 and $20 \mathrm{~cm}$ for measuring streaming potentials and $48 \mathrm{~cm}$ for measuring the electroosmotic flow by weight. The electrolyte solutions used consisted of $0.01 M$ chloride buffers of several $\mathrm{pH}$ values (Table I). The viscosity of these buffers was $0.001 \mathrm{~kg} / \mathrm{m} \cdot \mathrm{s}$, the dielectric constant $695 \cdot 10^{-12} \mathrm{~F} / \mathrm{m}$ and the density $1000 \mathrm{~kg} / \mathrm{m}^{3}$. The specific conductances, $\kappa$, of the buffers are also listed in Table I.

\section{RESULTS AND DISCUSSION}

\section{Streaming potential}

For the measurement of the streaming potential, Fig. 4 shows the dependence of the potential difference accross the capillary on the pressure drop. The electrolyte had a $\mathrm{pH}$ of 6.0 (Table I). A linear relationship was found for the streaming potential, as predicted by theory, with a regression coefficient of 0.99996 . The corresponding $\zeta$-potential was calculated from these experiments. As can be seen, it is independent of the $\Delta P$ introduced. From these values it was concluded that further experiments could be performed with a $\Delta P$ of $10^{5} \mathrm{~Pa}$ to achieve the maximal response.

In Fig. 5 the variation of the $\zeta$-potential with the $\mathrm{pH}$ of the electrolyte solution is shown. The data are the averages of three experiments, performed with the electrolytes given in Table I. The general deviation of the data is indicated. As can be seen from Fig. 5 , there is a strong dependence of $\zeta$-potential on $\mathrm{pH}$, resulting in a corresponding change in electroosmotic velocity (eqn. 1). The direction of EOF changes at a pH of $c a$. 3.5. The values given correspond to those reported in the literature ${ }^{2,15}$. 


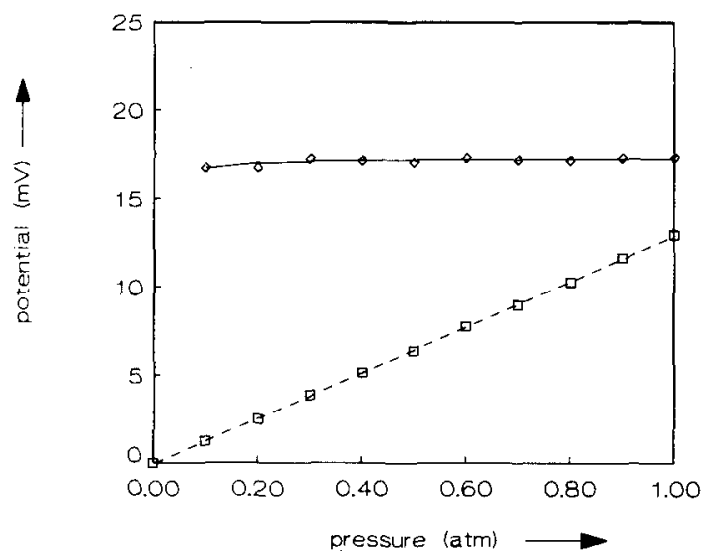

Fig. 4. Streaming potential (measured values) $(\square)$ and $\zeta$-potential (calculated values) $(\diamond)$ versus applied pressure drop. PTFE capillary, $15 \mathrm{~cm} \times 300 \mu \mathrm{m}$ I.D. Electrolyte, $\mathrm{pH} 6.0$ (Table I).

During the experiments it was found that for new capillaries exposed to electrolyte solutions, time is needed to obtain equilibrium. An example of such an adaptation period is presented in Fig. 6, which shows the time dependence of the $\zeta$-potential measured with a 1-min time interval. After exposure of a new PTFE capillary to an electrolyte solution of $\mathrm{pH} 6.0$ (Fig. 6, situation 1) a period of $20 \mathrm{~min}$ was required to reach a stable value. The change from a solution of $\mathrm{pH} 3.0$ to $\mathrm{pH} 4.8$ (Fig. 6, situation 2) required a period of nearly $120 \mathrm{~min}$. Therefore, care should be taken when changing the operational conditions.

\section{Weighing}

The weighing experiments were performed in the electrolyte system $(\mathrm{pH}$ 8.2) listed in Table I.

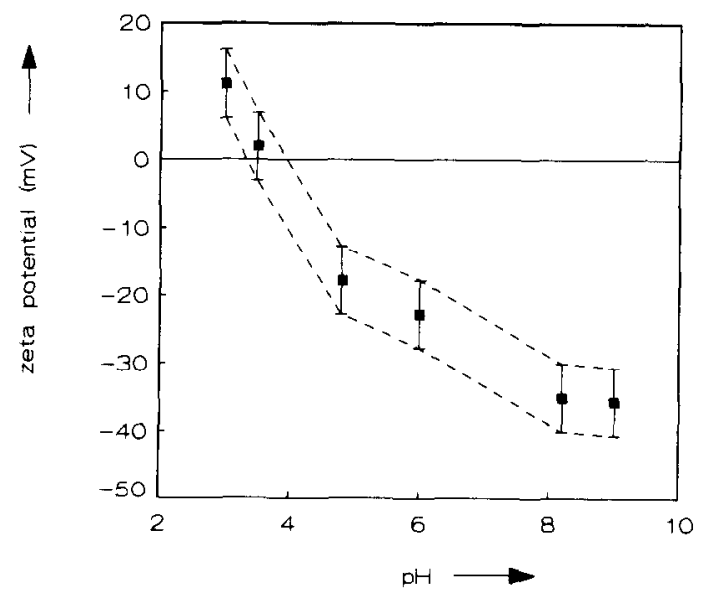

Fig. 5. $\zeta$-Potential (calculated value) obtained from streaming potential measurements versus $\mathrm{pH}$ of the electrolyte solution. PTFE capillary, $20 \mathrm{~cm} \times 300 \mu \mathrm{m}$ I.D. Electrolytes are listed in Table I. 


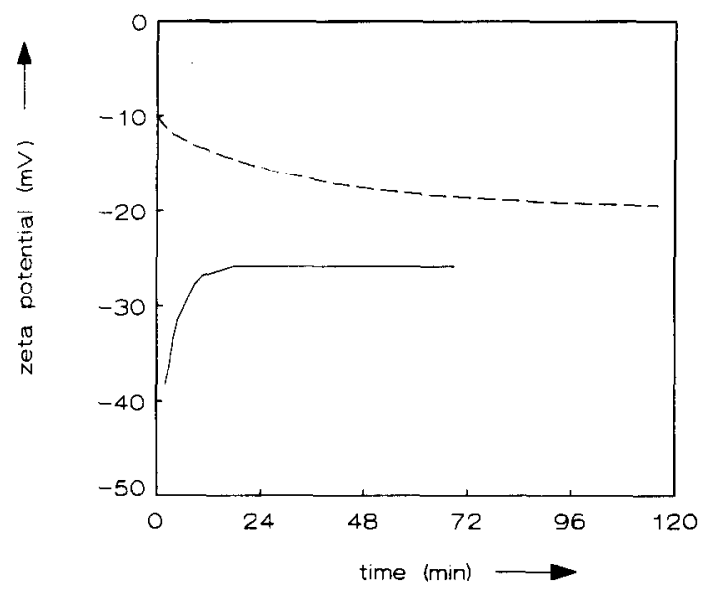

Fig. 6. Change of $\zeta$-potential with time after change in electrolyte conditions. Situation 1 (solid line), $\mathrm{pH} 6.0$ buffer and new capillary: situation 2 (broken line), change from pH 3.0 to $\mathrm{pH} 4.8$ buffer. Buffers are listed in Table I. PTFE capillary, $20 \mathrm{~cm} \times 300 \mu \mathrm{m}$ I.D.

Fig. 7A shows the dependence of the clectroosmotic velocity on the voltage applied over the capillary. Theory predicts an increase in flow with voltage. This is certainly visible, although at high voltages a deviation arises towards higher velocities. This can be explained by temperature effects. At high electric field strength an increase in electrolyte temperature causes a decrease in viscosity, resulting in a higher electroosmotic velocity (eqn. 1). In Fig. 7A it can be seen that at $6 \mathrm{kV}$ the linear

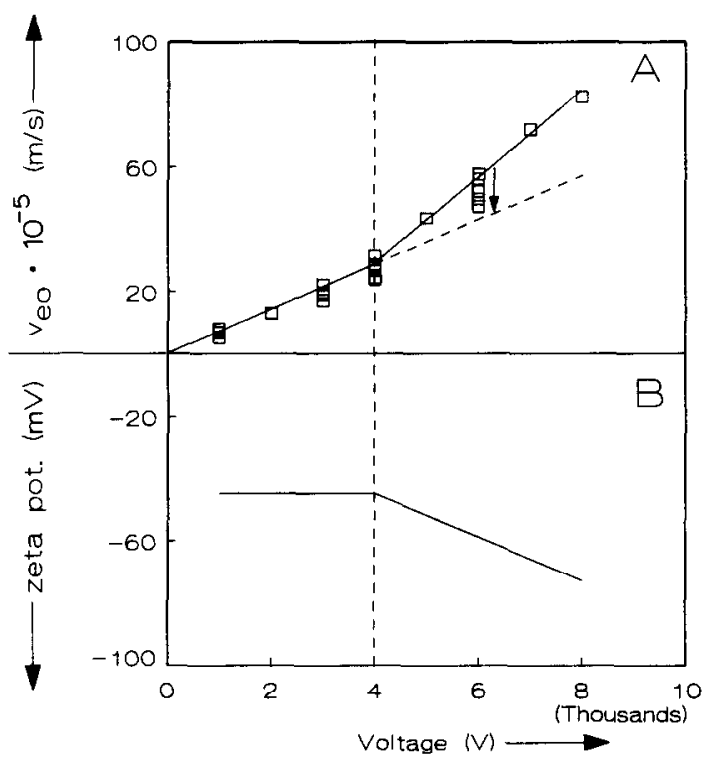

Fig. 7. (A) Electroosmotic velocity versus voltage applied, calculated from weighing experiments; (B) $\zeta$-potential, calculated from electroosmotic velocity versus voltage applied. PTFE capillary, $48 \mathrm{~cm} \times 300 \mu \mathrm{m}$ I.D. Electrolyte, $\mathrm{pH} 8.2$ (Table 1). 
relationship can be approached when sufficient time is used to allow the electrolyte to cool (indicated by the arrow). The $\zeta$-potentials calculated from the average electroosmotic velocities are shown in Fig. 7B. At voltages up to $4 \mathrm{kV}$ the $\zeta$-potential is constant and approximates the values in the literature ${ }^{2,15}$. At higher potential differences the observed $\zeta$-potential is higher.

The deviation in the experiments performed at a given field strength is also a result of temperature differences in the experiments. When an experiment is performed at a high electric field strength, the current density increases (up to $30 \%$ ) with time because of heating effects. After such an experiment it took several hours to regain the starting current density.

There is a difference between the value of $-35 \mathrm{mV}$ obtained with the streaming potential method at $\mathrm{pH} 8.2$ and the value of $-45 \mathrm{mV}$ resulting from the weighing measurements. From Figs. 5 and 7 it can be seen, however, that an inaccuracy of $c a$. $5 \mathrm{mV}$ in the data has to be accounted for. Also, it is difficult to compare these two values because data on temperature inside the capillary and therefore its influence on viscosity and mobilities are not known.

\section{CONCLUSIONS}

Data obtained with streaming potential measurements give better information on the behaviour of the materials because temperature effects are hardly present. However, more stable electrodes need to be made in order to measure the streaming potential better than the present inaccuracy of $5 \mathrm{mV}$. The method of determination of the EOF by weighing approaches the experimental conditions of electrophoresis and electrochromatography. It opens up the possibility for a complete characterization of the separation conditions, e.g., the capillary wall, solvent, surface-active components, viscosity and temperature.

For the weighing experiments the calculated $\zeta$-potentials are of minor interest, because the EOF is directly accessible. This on-line measurement of EOF opens up possibilities for regulation through a feedback to the power supply ${ }^{22}$. An increase in electroosmotic velocity is compensated for by means of a decrease in electric field strength. On-line computer data acquisition is, of course, necessary in this instance. The regulation of the electroosmotic flow is discussed elsewhere ${ }^{23}$.

\section{ACKNOWLEDGEMENTS}

The investigations were supported by the Netherlands Foundation for Chemical Research (SON) with financial aid from the Netherlands Organization for Scientific Research (NWO).

\section{REFERENCES}

1 V. Pretorius, B. J. Hopkins and J. D. Schieke, J. Chromatogr., 99 (1974) 23.

2 J. W. Jorgenson, K. D. Lukacs, Anal. Chem., 53 (1981) 1298.

3 M. M. Martin and G. Guiochon, Anal. Chem., 56 (1984) 614.

4 M. Martin, G. Guiochon, Y. Walbroehl and J. W. Jorgenson, Anal. Chem., 57 (1985) 559.

5 F. M. Everaerts, Th. P. E. M. Verheggen and J. L. M. van de Venne, J. Chromatogr., 123 (1976) 139.

6 J. Vacik and J. Zuska, J. Chromatogr., 91 (1974) 795. 
7 T. S. Stevens and H. J. Cortes, Anal. Chem., 55 (1983) 1365.

8 K. D. Lukacs and J. W. Jorgenson, J. High Resolut. Chromatogr. Chromatogr. Commun., 8 (1985) 407.

9 H. H. Lauer and D. McManigill, Anal. Chem., 58 (1986) 166.

10 B. J. Herren, S. G. Shafer, J. van Alstine, J. M. Harris and R. S. Snyder, J. Colloid Interface Sci., 115 (1987) 46.

11 A. J. Rutgers, M. de Smet and W. Rigole, in H. van Olphen and K. J. Mysels (Editors), Physical Chemistry: Enriching Topics from Colloid and Surface Science, Theorex, La Jolla, CA, 1975.

12 R. J. Hunter, Zeta Potential in Colloid Science, Academic Press, London, 1981.

13 R. A. van Wagenen, J. D. Andrade and J. B. Hibbs, Jr., J. Electrochem. Soc., 123 (1976) 1438.

14 R. A. van Wagenen and J. D. Andrade, J. Coloid Interface Sci., 76 (1980) 305.

15 J. C. Reijenga, G. V. A. Aben, Th. P. E. M. Verheggen and F. M. Everaerts, J. Chromatogr., 260(1983) 241.

16 K. D. Altria and C. F. Simpson, Anal. Proc., 23 (1986) 453.

17 K. D. Altria and C. F. Simpson, Chromatographia, 24 (1987) 527.

18 J. T. Davies and E. K. Rideal, Interfacial Phenomena, Academic Press, New York, 2nd ed., 1963.

19 A. W. Adamson, Physical Chemistry, Interscience, New York, 2nd ed., 1967.

20 C. L. Rice and R. Whitehead, J. Phys. Chem., 69 (1965) 4017.

21 P. T. Thomson, Ph.D. Thesis, Pittsburgh, PA, 1956.

22 B. J. Wanders, A. A. A. M. van de Goor, F. M. Everaerts and C. A. Cramers, The Netherlands Patent Application No. 8802273.

23 B. J. Wanders, A. A. A. M. van de Goor and F. M. Everaerts, J. Chromatogr., 470 (1989) 89. 